\title{
CURVING PERFORMANCE SIMULATION OF BOGIE ANGLE LINKED STEERING TRUCK
}

\author{
YASUHIRO UMEHARA, SHOGO KAMOSHITA \& YUSUKE YAMANAGA \\ Vehicle Structure Technology Division, Railway Technical Research Institute, Japan
}

\begin{abstract}
A type of bogie angle linked steering truck adopts a method of steering the wheelsets depending on the relative yawing angle between the car body and the truck. This kind of truck has no risk of the reverse steering and is able to decrease the wheel lateral force greatly in the circular curve section. However, compared to the general bolster trucks, the steering truck has problems such as complicated truck maintenance work because of the complicated truck structure equipped with steering devices such as a steering links. Therefore, in order to devise a type of steering truck with a structure as simple as possible, the authors carried out a fundamental study of steering trucks equipped with fewer steering links than the existing one. In this paper, the authors report on the curving performance simulation analysis of a railway vehicle equipped with the steering truck, and also its result that the influence of the position and the number of steering links was confirmed. Regarding the types of the mounting position of the steering links, there are eight types including four links and none. The authors compared the curving performance by the lateral force of a leading axle in the curve section. In the simulation results, the lateral force under four-link condition was the smallest in the circular curve section. However, it increased in the trailing transition curve section. On the other hand, in the case of two links, the lateral force was greatly reduced in the trailing transition curve section.

Keywords: bogie angle linked steering truck, steering bogie, steering link, lateral force.
\end{abstract}

\section{INTRODUCTION}

In order to increase the curve passing speed of railway vehicles, it is necessary to pay attention to the lateral force which increases as the running speed increases. The lateral force causes the wear of the wheel and the rail. Particularly the significant lateral force increases the risk of the derailment. It is a steering truck where the lateral force can be reduced by changing the direction of the wheelset during the curve section that can be cited as one of the methods of reducing the lateral force, and so far various types of steering trucks have been researched and developed. The bogie angle linked steering truck (Fig. 1) can considerably reduce the lateral force in the circular curve section and there is almost no danger of the reverse steering [1]. Therefore, this steering truck has already been used on the commercial line in Japan, contributing to the reduction of the lateral force. However, compared to general bolster trucks, the steering truck has problems such as complicated truck maintenance work because of the complicated truck structure equipped with steering devices such as steering links. Moreover, the lateral force reduction in the transition curve section by the steering truck is smaller than in the circular curve section, and the literature suggests there is still room for improvement [2]. Therefore, a type of steering truck with a structure as simple as possible where the lateral force in the transition curve can be reduced is required.

In this paper, the authors carried out a fundamental study of steering trucks equipped with fewer steering links than the existing one. The authors report on the curving performance simulation analysis of a railway vehicle equipped with the steering truck. From the simulation results, the authors confirmed the influence on the lateral force produced by the position and the number of steering links. 


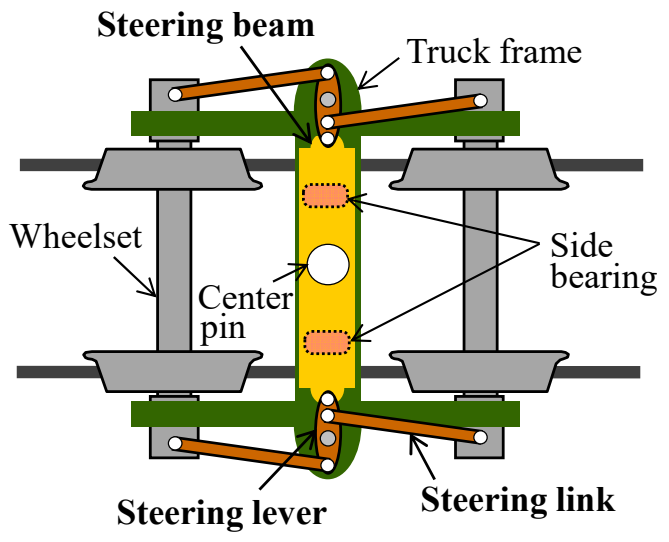

(a) Straight section

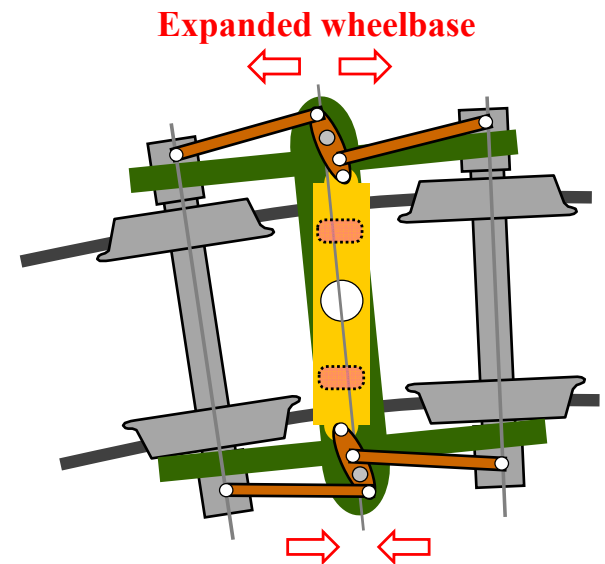

Shortened wheelbase

Figure 1: Schematic illustration of the bogie angle linked steering truck.

\section{STRUCTURE AND PERFORMANCE OF BOGIE ANGLE LINKED STEERING TRUCK}

The fundamental structure of the bogie angle linked steering truck is shown in Fig. 1(a). The steering beam is mounted on the truck frame via the side bearings and can yaw around the center pin. The side bearing is an element that gives frictional force appropriate for turning a truck in order to ensure the running stability at a high speed. The steering beam and the car body yaw together since they are connected by the bolster anchors. The steering levers and the steering links are configured so that the wheelsets yaw in accordance with the relative yawing angle between the steering beam and the truck frame (bogie angle). Therefore, in the curve section, the steering levers and the steering links expand the outer wheelbase and shorten the inner wheelbase depending on the bogie angle (Fig. 1(b)).

In Fig. 2 comparison of the results between the conventional truck and the steering truck in a running test is shown. This figure shows the outer lateral force of the leading wheelset in the curve section (radius of the curve: $402 \mathrm{~m}$, cant: $90 \mathrm{~mm}$ ). As a result, it is confirmed that the steering truck drastically reduced the lateral force in the circular curve section. On the other hand, the reduction effect is small in the transition curves. In particular, it is confirmed that the steering truck conversely increased the lateral force in the trailing transition curve. The following points can be given as the reasons. First, the leading truck was steering in the straight section due to the bogie angle caused by the fact that the trailing truck remained in the curve section. Second, the steering beam was not able to return to the perfect straight state because the side bearings had hysteresis characteristics. There is a tendency for the flange climb derailment to occur at the initial section at the trailing transition curve because the wheel load on outer rail side of the leading wheelset decreases [3]. Therefore, it is effective to reduce the lateral force at the trailing transition curve in order to reduce the derailment quotient. 


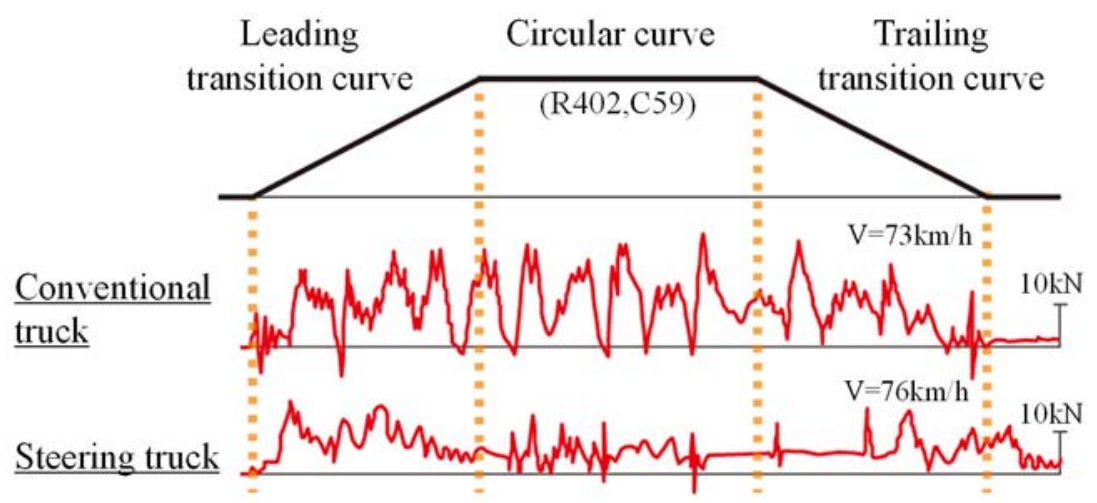

Figure 2: Running test results of the outer lateral force [2].

\section{EVALUATION BY THE DYNAMICS ANALYSIS OF A RAILWAY VEHICLE}

\subsection{Railway vehicle model}

The authors created a dynamics analysis model of a railway vehicle with the steering truck (Fig. 3). This three-dimensional model was built on the multi-body simulation software (SIMPACK). The steering device was represented by links and spring elements. The track measurement data of the test line in Railway Technical Research Institute was used for the shape of the simulation line. The test curve has a curve radius of $100 \mathrm{~m}$ and a cant of $90 \mathrm{~mm}$. In addition, the specifications of the railway vehicle were assumed to be those of a conventional express train. In anticipation of the running tests by use of an actual vehicle in the future, the vehicle model mounts a steering truck on the leading side and a normal bolsterless truck on the trailing side.

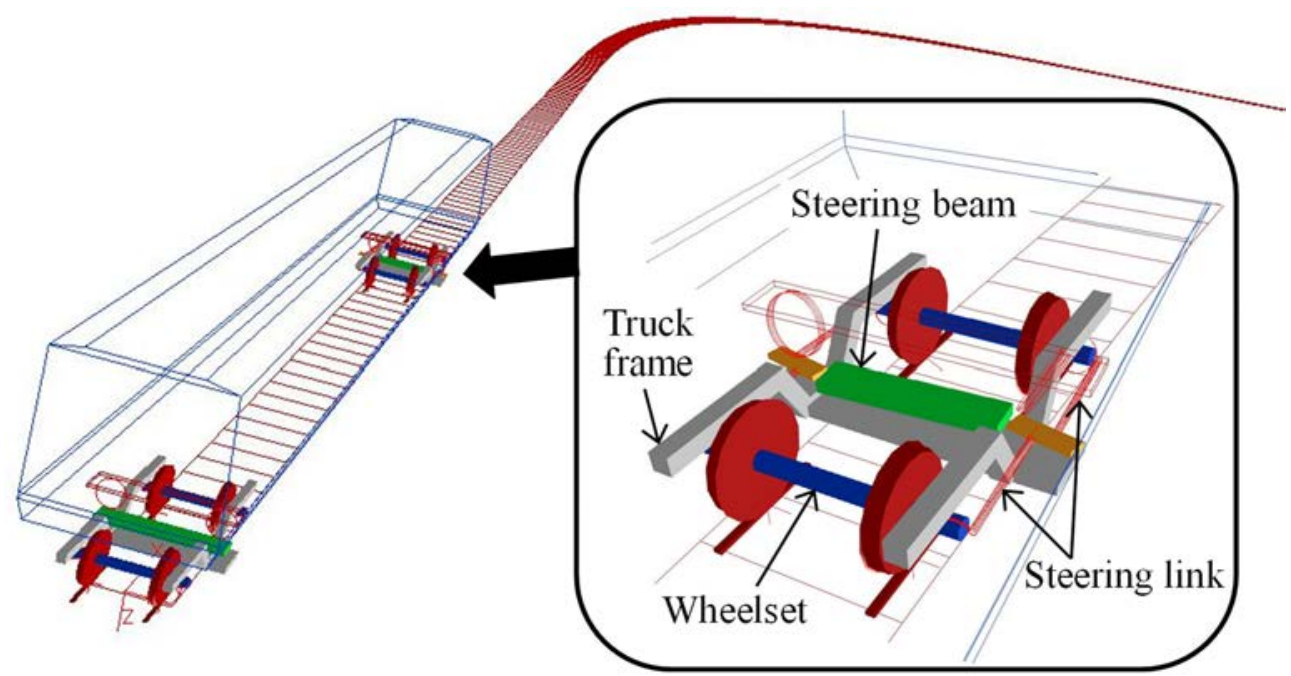

Figure 3: Dynamics analysis model of a railway vehicle with the steering truck. 
The friction of the side bearing has strong nonlinearity and greatly influences the lateral force in the transition curve section. Therefore, the precise modeling is required. In the bench test, the authors measured the friction of the bearing was generated in the actual truck, and reflected the measured value in the simulation model. Fig. 4 shows the rotational constraint model of the steering truck. In Fig. 4(a) the relationship between the bogie angle and the friction of the side bearing is shown. Firstly, the spring element acts as the resistance force until the steering beam starts to turn. Secondly, the friction decreases to the kinetic friction when the steering beam turns. Thirdly, the spring elements acts as the restoring force when the bogie angle decreases as the bogie nearing the straight section after the turning of the steering beam stops. The sliding part and the spring/damper element were expressed as the series coupling assuming the hysteresis (Fig. 4(b)). The rotational constraint of the truck is expressed by the eqns (1) and (2) according to the state of the steering beam

$$
\begin{array}{ll}
F=k\left(|r|-\left|r_{0}\right|\right)+c \cdot v & |F| \leq f_{s}, \\
F=f_{k} \cdot \operatorname{sign}(v) & |F|>f_{s},
\end{array}
$$

where $F$ is the rotational constraint of the truck, $f_{s}$ is the static friction of the side bearing, $f_{k}$ is the kinetic friction of the side bearing, $k$ is the spring constant, $c$ is the damping coefficient, $r$ is the displacement accompanying the bogie angle, $r_{0}$ is the displacement accompanying the bogie angle when the turning of the steering beam stops, $v$ is the relative velocity between the car body) and the truck frame.

\subsection{Test conditions of the steering links}

In order to devise a type of steering truck with a structure as simple as possible, the authors carried out a fundamental study of steering trucks where reduced the number of steering links is reduced from four to two. Fig. 5 shows the types of the mounting position of the steering links, that is, eight types including four links and none. "Type A" is a normal bogie angle

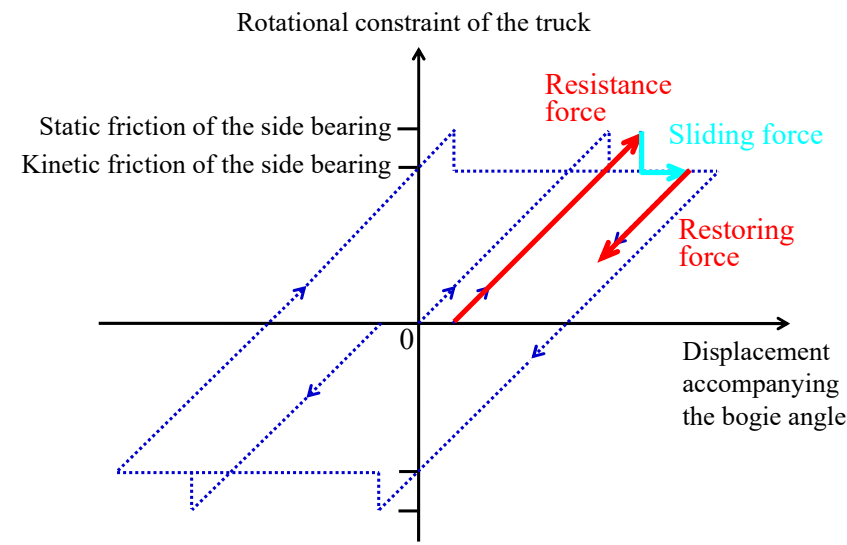

(a)

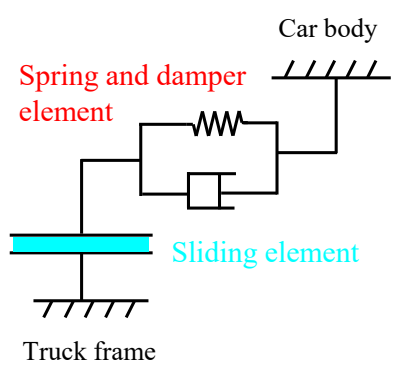

(b)

Figure 4: Rotational constraint model of the bogie angle linked steering truck. (a) Relationship between the bogie angle; (b) Model of the rotational constraint and the rotational constraint. 


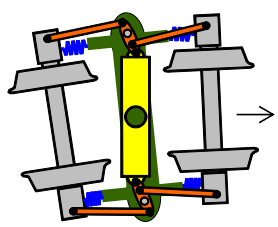

Type A

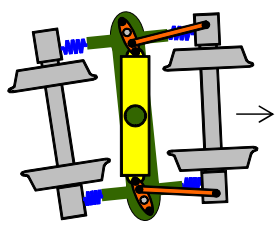

Type C

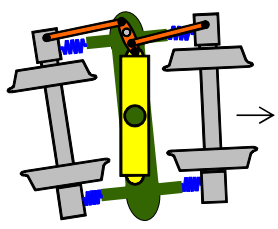

Type E

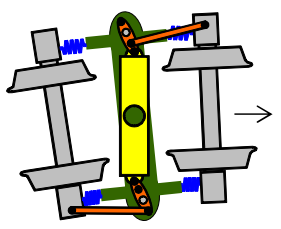

Type G

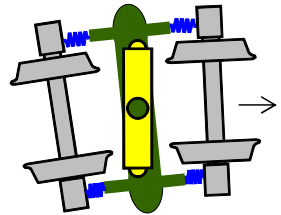

Type B

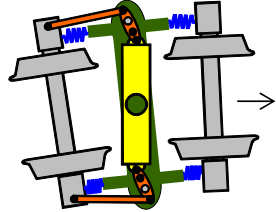

Type D

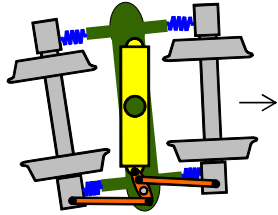

Type F

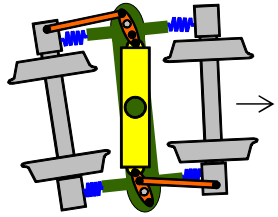

Type $\mathrm{H}$

Figure 5: Mounting position types of the steering links.

linked steering truck. "Type B" is equivalent to a conventional truck without links. However, the longitudinal stiffness of the axle box suspension is about one-third of that of a normal truck. "Type C" and "Type D" are presented for the purpose of testing the steering links provided that they are connected to only one wheelset. "Type E" and "Type F" are presented for the purpose of testing the steering links provided that they are connected to only the outer rail side and the inner rail side respectively. "Type G" and "Type H" are presented for the purpose of testing the steering links provided that they are mounted diagonally.

\subsection{Results of the dynamics analysis}

Figs 6-8 show the inner and outer wheel lateral force of the leading wheelset in the curve section. When the direction in which the wheel pushes is outwards, the wheel lateral force is represented by a positive value. In Fig. 6, the curvature was added to make it easy to judge the curve section. Type A and Type B were described in all graphs in order to facilitate the comparison. In the circular curve section, the lateral force reduction effect of Type A equipped with four steering links was understandably high. Next, that of Type D equipped with the steering links at the second wheelset was high. Because the rotational moment of the truck frame decreases by reducing the longitudinal creep force on the second wheelset, the lateral force of the leading wheelset decreases. The steering truck of this type has already been used in the subway line in Japan [4]. As in Fig. 2, the lateral force reduction effect in the transition curve section of Type A was small as compared with the reduction effect in the circular section. Fig. 9 shows the mean outer and inner lateral force in the trailing transition curve. In the types of two-link (Type E-H), the outer and inner lateral force was greatly reduced in the trailing transition curve section. For this reason, the authors think as follows. When the front truck enters the trailing transition curve section, the steering links start to move the wheelset in a parallel direction to the bogie frame. Moreover, since the second wheelset of this types of two-link has a small constraint of the front wheelset and the truck frame, the second wheelset moves outward from the center of the track by the steering link on one side. At this time, the longitudinal creep force of the second wheelset rapidly decreases and reverses. As a result, the rotational moment of the truck decreases, and the lateral force of the leading wheelset decreases. 

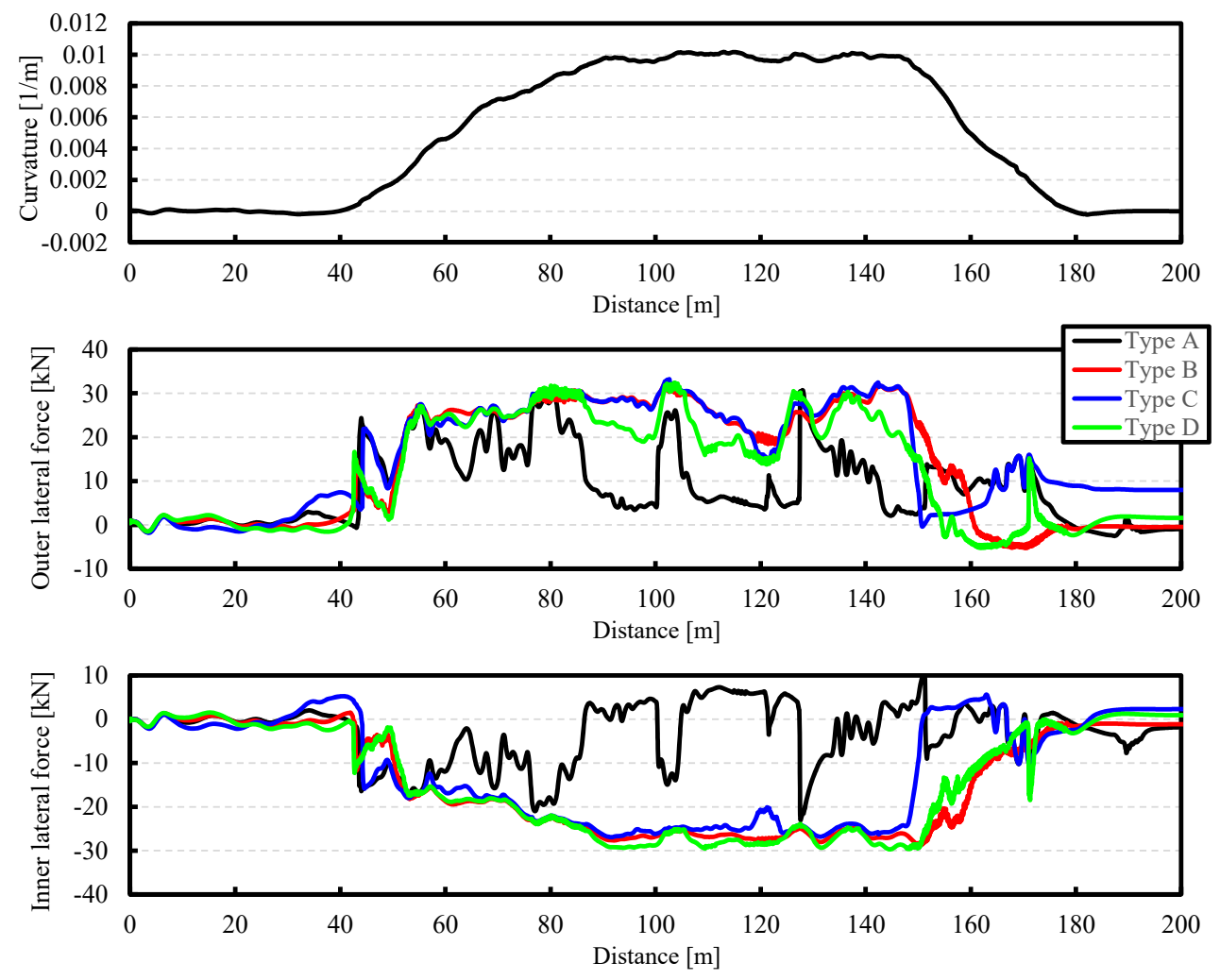

Figure 6: Simulation results of the lateral force in the curve section (Type A, B, C, D).
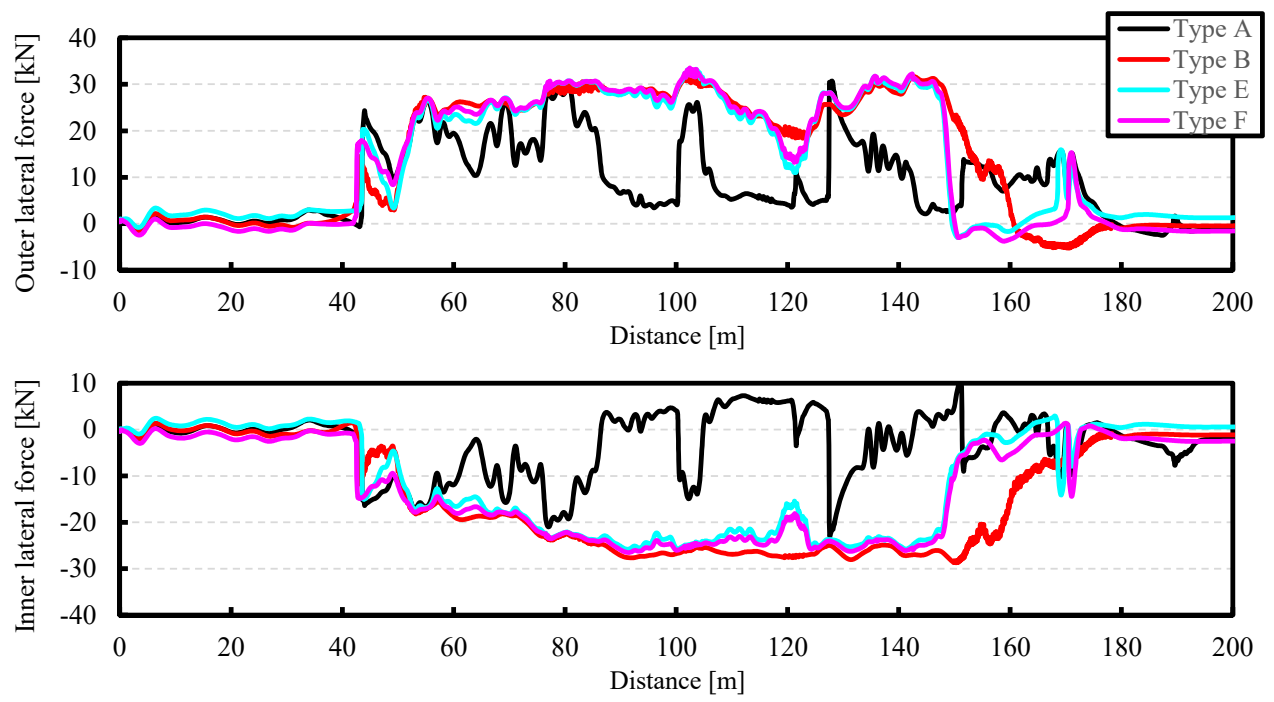

Figure 7: Simulation results of the lateral force in the curve section (Type A, B, E, F). 

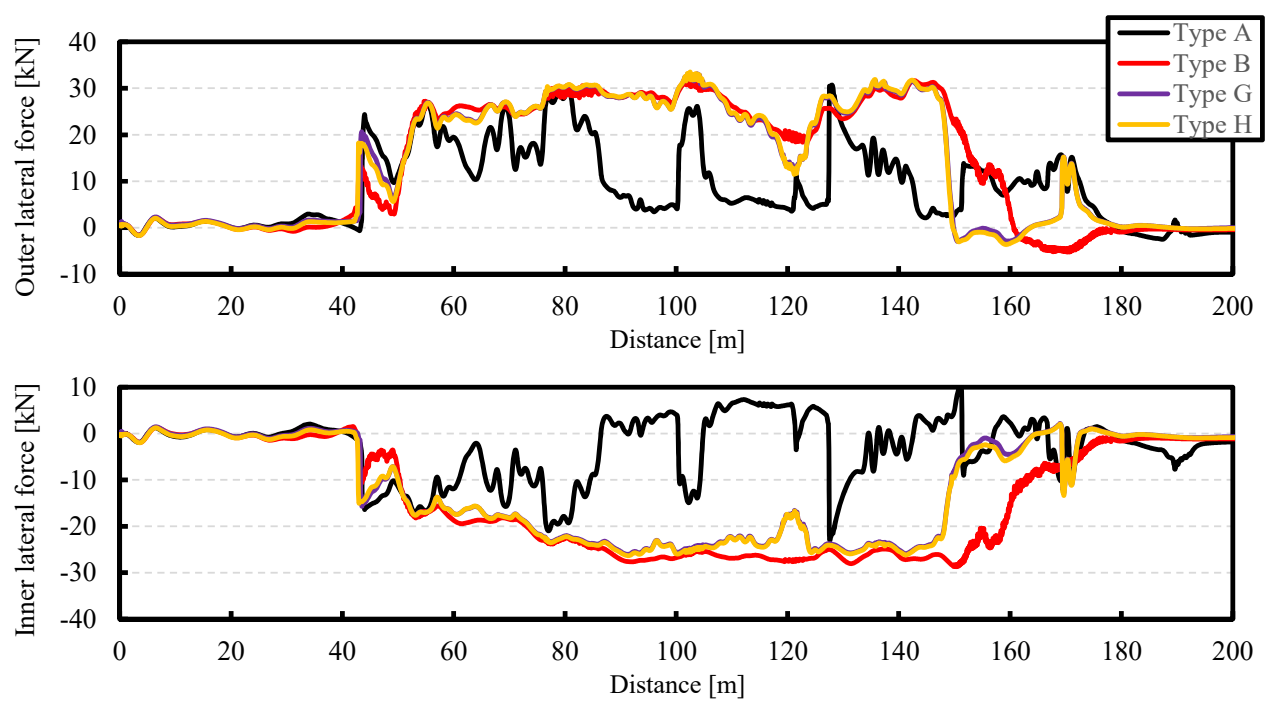

Figure 8: Simulation results of the lateral force in the curve section (Type A, B, G, H).

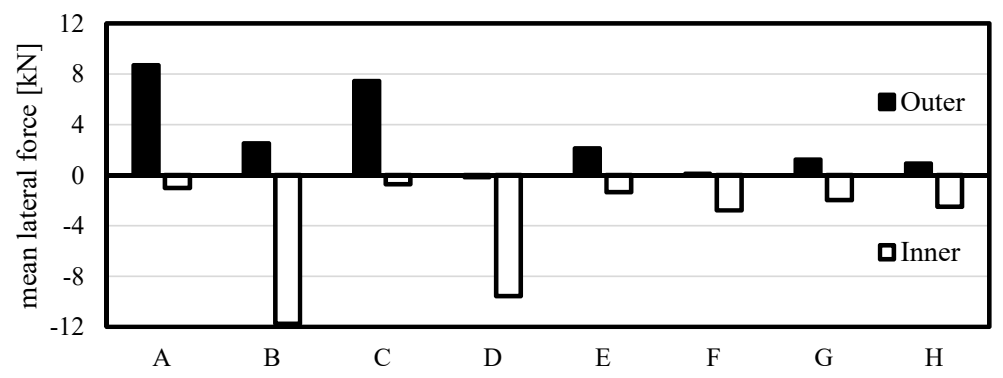

Figure 9: Mean outer and inner lateral force in the trailing transition curve.

\section{CONCLUSION}

The authors report on the curving performance simulation analysis of a railway vehicle equipped with the steering truck, where the authors confirmed the influence of position and number of steering links. Regarding the types of the mounting position of the steering link, there are eight types including four links and none. As a result of the simulation, the lateral force under four-link condition was the smallest in the circular curve section. However, it increased in the trailing transition curve section. On the other hand, in the case of two links, the outer and inner lateral force was greatly reduced in the trailing transition curve section. In the future, the authors will verify the optimization of the steering lever ratio and the reason why the reduction effect of the lateral force was small in the circular curve. Moreover, the authors would like to carry out running tests and verify the accuracy of the simulation result and the mechanism of the lateral force reduction in the trailing transition curve section. 


\section{REFERENCES}

[1] Kobayashi, H., Okamoto, I. \& Akiyama Y., The forced steering tilt truck for diesel limited express. QR of RTRI, 41(1), pp. 16-20, 2000.

[2] Sato, E. et al., Lateral force between wheel and rail during curve negotiation of limited express diesel car with forced steering bogies. Vehicle System Dynamics Supplement, 37, pp. 678-689, 2002.

[3] Accident Investigation Commission, Report on the train derailment at Nakameguro station on the Tokyo Metoro Co. Hibiya line, 2000 (in Japanese).

[4] Togami, Y. et al., The development of the new type steering bogie, part 2. Proceedings of the 9th International Conference on Railway Bogies and Running Gears, pp. 57-63, 2013. 